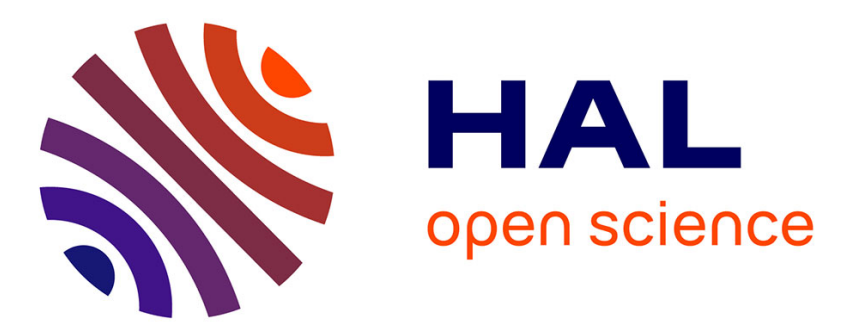

\title{
Characterization of Uranium in Bituminized Radioactive Waste Drums by Self-Induced X-Ray Fluorescence
}

\author{
Patrick Pin, Bertrand Perot
}

\section{To cite this version:}

Patrick Pin, Bertrand Perot. Characterization of Uranium in Bituminized Radioactive Waste Drums by Self-Induced X-Ray Fluorescence. IEEE Transactions on Nuclear Science, 2014, 61 (4), pp.21312136. 10.1109/TNS.2013.2283726 . cea-01992412

\section{HAL Id: cea-01992412 https://hal-cea.archives-ouvertes.fr/cea-01992412}

Submitted on 4 May 2020

HAL is a multi-disciplinary open access archive for the deposit and dissemination of scientific research documents, whether they are published or not. The documents may come from teaching and research institutions in France or abroad, or from public or private research centers.
L'archive ouverte pluridisciplinaire HAL, est destinée au dépôt et à la diffusion de documents scientifiques de niveau recherche, publiés ou non, émanant des établissements d'enseignement et de recherche français ou étrangers, des laboratoires publics ou privés. 


\title{
Characterization of Uranium in Bituminized Radioactive Waste Drums by Self-Induced X- Ray Fluorescence
}

\author{
Patrick Pin, Bertrand Pérot
}

\begin{abstract}
This paper reports the experimental qualification of an original uranium characterization method based on fluorescence $X$ rays induced by the spontaneous gamma emission of bituminized radioactive waste drums. The main $661.7 \mathrm{keV}$ gamma ray following the ${ }^{137} \mathrm{Cs}$ decay produces by Compton scattering in the bituminized matrix an intense photon continuum around $100 \mathrm{keV}$, i.e. in the uranium $X$-ray fluorescence region. "Self-induced" X-rays produced without using an external source allow a quantitative assessment of uranium as ${ }^{137} \mathrm{Cs}$ and uranium are homogeneously mixed and distributed in the bituminized matrix. The paper presents the experimental qualification of the method with real waste drums, showing a detection limit well below $1 \mathrm{~kg}$ of uranium in $20 \mathrm{~min}$ acquisitions while the usual gamma rays of ${ }^{235} \mathrm{U}(185.7 \mathrm{keV})$ or ${ }^{238} \mathrm{U}\left(1001.0 \mathrm{keV}\right.$ of ${ }^{234 \mathrm{~m}} \mathrm{~Pa}$ in the radioactive decay chain) are not detected. The relative uncertainty on the uranium mass assessed by self-induced X-ray fluorescence (SXRF) is about $50 \%$, with a 95\% confidence level, taking into account the correction of photon attenuation in the waste matrix. This last indeed contains high atomic numbers elements like uranium, but also barium, in quantities which are not known for each drum. Attenuation is estimated using a peak-to-Compton ratio to limit the corresponding uncertainty. The SXRF uranium masses measured in the real drums are in good agreement with long gamma-ray spectroscopy measurements (1001.0 $\mathrm{keV}$ peak) or with radiochemical analyses.
\end{abstract}

Index Terms-Gamma-ray spectroscopy, self-induced X-ray fluorescence, bituminized radioactive waste

\section{INTRODUCTION}

$\mathrm{W}$ HITHIN the framework of the cleaning operation of Marcoule reprocessing plant UP1, in France, the French Atomic and Renewable Energy Commission (CEA) has developed a scale one mock-up of an industrial measurement system for $225 \mathrm{~L}$ radioactive waste drums containing bituminized radioactive sludge originating from the effluent

Manuscript submitted on 2 July, 2013. This work was supported by former CODEM economic group gathering CEA, EDF (French public utility) and AREVA NC Marcoule (historic operator of UP1 reprocessing plant). CODEM was in charge of UP1 dismantling operations and in particular radioactive waste retrieval.

P. Pin was with CEA, DEN, Cadarache, Nuclear Measurement Laboratory, F-13108 Saint-Paul-lez-Durance, France. He is now with AREVA NC, La Hague, F-50444 Beaumont-Hague Cedex, France (e-mail: patrick.pin@areva.com).

B. Pérot is with CEA, DEN, Cadarache, Nuclear Measurement Laboratory, F-13108 Saint-Paul-lez-Durance, France (e-mail: bertrand.perot@ cea.fr). treatment. The objective of the measurement system was to determine the radiological inventory of each waste package, with a special care to minimize the uncertainty on the total alpha activity. A mock-up was built to qualify the design and performances assessed by numerical simulation [1]. The system consists of a ${ }^{60} \mathrm{Co}$ gamma imaging station to determine the waste matrix filling height and density, a neutron cell with a pulsed DT neutron generator to assess ${ }^{235} \mathrm{U}$ and ${ }^{239} \mathrm{Pu}$, as well as ${ }^{240} \mathrm{Pu}$ in passive mode, and the two gamma-ray spectrometers sketched in Fig. 1.

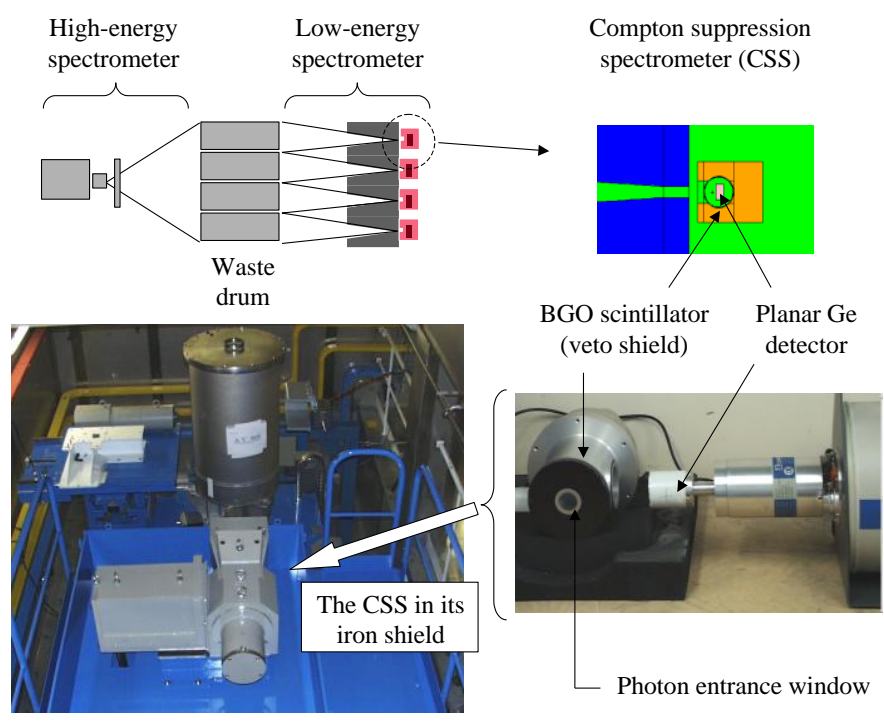

Fig. 1. Top, left panel: "High- and Low-Energy" Spectrometers (HES, LES); Top, right: MCNP model of the Compton Suppression Spectrometer (CSS); Bottom, left: LES global view (shielded CSS aiming at the drum behind a 75 $\mathrm{cm}$ long iron collimator); bottom, right: CSS prototype.

The CSS is made of a planar high-purity germanium (HPGe) detector surrounded by a $\mathrm{BGO}\left(\mathrm{Bi}_{4} \mathrm{Ge}_{3} \mathrm{O}_{12}\right)$ veto shield. It is dedicated to "low" energy photons ranging from the $59.5 \mathrm{keV}$ line of ${ }^{241} \mathrm{Am}$, for which this detector was optimized, to the $661.7 \mathrm{keV}$ gamma ray of ${ }^{137 \mathrm{~m}} \mathrm{Ba}$, radioactive daughter of ${ }^{137} \mathrm{Cs}$ [2], [3]. The HPGe detector aims at the bituminized waste through an iron collimator with different apertures, depending on the gamma emission rate of the waste, which divides the drum in four vertical sectors. The mock-up of the gamma station shown in Fig. 1 just includes one CSS and the drum is elevated to measure successively the four sectors, but four stacked CSS were planned for the industrial 
system. A second gamma spectrometer based on a $100 \%$ relative efficiency HPGe coaxial detector is used for "high" energy photons, i.e. from $661.7 \mathrm{keV}$ to the $2614.5 \mathrm{keV}$ gamma ray of ${ }^{208} \mathrm{Tl}$, from the ${ }^{232} \mathrm{Th}$ decay chain. The $100 \%$ HPGe detector measures the drum in open geometry. It is shielded by lead plates with a thickness adjusted to the radiation level of each package.

The knowledge of the uranium mass is needed to minimize the uncertainty on the ${ }^{239} \mathrm{Pu}$ mass measured by pulsed neutron interrogation, because of the presence of a significant uranium quantity in each drum, i.e. around one kilogram in average and several kilograms in some drums. The prompt and delayed fission neutron signals induced by a pulsed neutron generator are recorded. They mainly depend on ${ }^{235} \mathrm{U}$ and ${ }^{239} \mathrm{Pu}$, but ${ }^{238} \mathrm{U}$ also contribute to the delayed signal [1]. Therefore, the ${ }^{238} \mathrm{U}$ quantity must be assessed to minimize uncertainty on the ${ }^{239} \mathrm{Pu}$ mass extracted from these two signals. As the ${ }^{235} \mathrm{U} /{ }^{238} \mathrm{U}$ ratio is not well known for each drum (it is approximately known as a function of the drum production period), an alternative is to measure ${ }^{238} \mathrm{U}$ by gamma-ray spectroscopy. However, the usual $1001.0 \mathrm{keV}$ line of ${ }^{234 \mathrm{~m}} \mathrm{~Pa}$, in radioactive equilibrium in the ${ }^{238} \mathrm{U}$ decay chain, requires much longer acquisitions than the 20 min imposed to characterize the thousands of waste drums present in UP1 plant.

Therefore, we proposed to measure the total uranium mass (the ${ }^{238} \mathrm{U}$ mass fraction being larger than 99\%) using its fluorescence $\mathrm{X}$ rays induced by the intense Compton continuum produced in the waste matrix by the $661.7 \mathrm{keV}$ gamma rays [4], [5]. This photon excitation spectrum is maximum around $100 \mathrm{keV}$, leading to significant photoelectric absorption in uranium followed by X-ray fluorescence. The intense $\mathrm{K}_{\alpha} \mathrm{X}$ rays at $98.4 \mathrm{keV}(100 \%)$ and $94.7 \mathrm{keV}(\sim 62 \%)$ are clearly visible in Fig. 2. The "self-induced $\mathrm{X}$-ray fluorescence" (SXRF) method allows a quantitative uranium assessment because it is homogeneously mixed and distributed with ${ }^{137} \mathrm{Cs}$ in the bituminized matrix. SXRF is already employed to assess the plutonium to uranium elemental ratio in solid spent fuel, or in dissolution aliquots, using the $98.4 \mathrm{keV}$ and $103.8 \mathrm{keV} \mathrm{K}_{\alpha 1}$ lines of $\mathrm{U}$ and $\mathrm{Pu}$, respectively, see for instance [6] and references therein. However, to our knowledge, SXRF was neither applied in the field of radioactive waste characterization, nor for an absolute measurement of the uranium quantity. Additionally, the SXRF signal is here corrected for low-energy photon attenuation (Compton continuum in the $100 \mathrm{keV}$ region and $98.4 \mathrm{keV}$ uranium $\mathrm{X}$ ray) with another innovative method based on a peak-to-Compton ratio [7]. The signal is indeed extremely sensitive to the concentration of high atomic numbers elements in the bituminized waste, like uranium $(Z=92)$ and barium ( $\mathrm{Z}=56$ ). This paper presents the experimental qualification of SXRF through real waste drum measurements.

\section{Detailed PRINCIPLE}

The gamma-ray spectra of five real waste drums are reported in Fig. 2, showing mainly the $661.7 \mathrm{keV}$ full-energy peak and the associated Compton continuum. The radioactive decay of ${ }^{137} \mathrm{Cs}$ (30.17 year period) is followed by the isomeric transition of ${ }^{137 \mathrm{~m}} \mathrm{Ba}(2.55 \mathrm{~min})$ with the emission of a $661.7 \mathrm{keV}$ gamma ray. Uranium, lead and bismuth fluorescence X-rays (see details further in Fig. 7 and 8) are due to the presence of uranium in the bituminous mix, bismuth in the CSS veto shield (BGO scintillator), lead in an external shield surrounding all the CSS (not shown in Fig. 1) as well as in the bituminized matrix (but in minute quantity).

All spectra are normalized to the number of counts (net area) in the $661.7 \mathrm{keV}$ peak of drum \#1. The presence of high$\mathrm{Z}$ elements clearly attenuates the Compton continuum at low energy. The peak-to-Compton ratio can thus be used to correct for low energy photon attenuation [7]. The density of the bituminous mix and the quantity of uranium and barium present in these five drums are given in Table I. Density is assessed with the ${ }^{60} \mathrm{Co}$ gamma radiography station, with a $95 \%$ confidence interval of $\pm 10 \%$. The uranium mass is here determined by $80,000 \mathrm{~s}$ acquisitions ( $1001.0 \mathrm{keV}$ line) for drums \#1, \#2 and \#3. This was however not possible for more recent drums \#4 and \#5 because of interfering gamma rays at 996.3 and $1004.7 \mathrm{keV}\left({ }^{154} \mathrm{Eu}, 8.6\right.$ year period). In these drums, barium and uranium masses are given by radiochemical analyses on radioactive sludge before mixing with bitumen. For drum \#4, the available masses are averaged over year 1997. The waste producer also provided for drum \#4 another mass of barium deduced from the waste inventory of year 1997. Systematic online quality controls were not performed when the three older drums were produced, but barium was not used in the process at that time. This was confirmed by radiochemical analyses on samples extracted from six historic drums including drums \#1 and \#3.

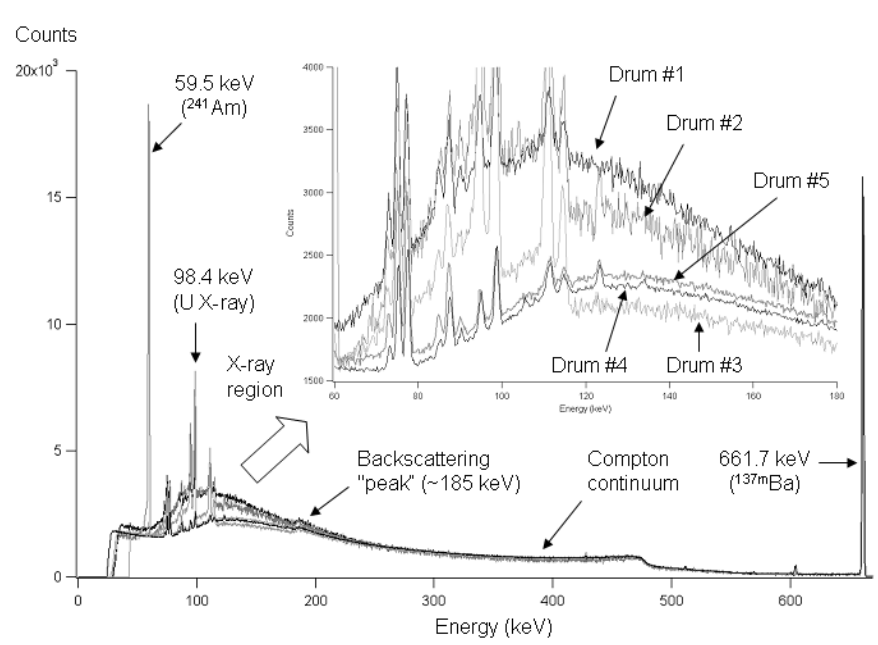

Fig. 2. Gamma-ray spectra of five $225 \mathrm{~L}$ bituminized waste drums corresponding to $20 \mathrm{~min}$ acquisitions. Spectra are normalized to the $661.7 \mathrm{keV}$ net area of drum \#1. The X-ray region is detailed in further Fig. 7 and 8. 
TABLE I. DENSITY OF THE DRUMS AND HIGH-Z ELEMENTS.

\begin{tabular}{|c|c|c|c|c|}
\hline Drum & $\begin{array}{c}\text { Production } \\
\text { year }\end{array}$ & Density & $\begin{array}{c}\mathrm{U} \text { mass } \\
(\mathrm{kg})\end{array}$ & $\begin{array}{c}\text { Ba mass } \\
(\mathrm{kg})\end{array}$ \\
\hline$\# 1$ & 1968 & 1.40 & $0.84^{a}$ & No Ba \\
\hline \#2 & 1971 & 1.20 & $3.50^{a}$ & No Ba \\
\hline \#3 & 1972 & 1.30 & $7.56^{a}$ & No Ba \\
\hline \#4 & 1997 & 1.34 & $0.85^{b}$ & $5.6^{\mathrm{c}}$ or $9.4^{\mathrm{d}}$ \\
\hline \#5 & 1998 & 1.35 & $0.94^{e}$ & $5.1^{e}$ \\
\hline \multicolumn{5}{|c|}{ Gamma-ray spectroscopy with a $95 \%$ confidence interval of $\pm 20 \%$. } \\
\hline \multicolumn{5}{|c|}{$\begin{array}{l}\text { Radiochemical analyses performed by the waste producer (average of } \\
1997 \text { compositions) with a }[-43 \% ;+21 \%] \text { confidence interval. }\end{array}$} \\
\hline \multicolumn{5}{|c|}{${ }^{d}$ Average chemical analyses of year 1997: $9.4 \mathrm{~kg}[-43 \% ;+33 \%]}$. \\
\hline
\end{tabular}

The level of the Compton continuum in the $100 \mathrm{keV}$ region is used to estimate self-absorption of low energy photons in the bituminized matrix, like the $59.5 \mathrm{keV}$ gamma ray of ${ }^{241} \mathrm{Am}$ as detailed in [3]. It can be used here to correct for the attenuation of the SXRF sensitivity coefficient, $\mathrm{C}_{\mathrm{SXRF}}\left(\mathrm{kg}^{-1}\right)$, which links the most intense uranium X-ray net area $\mathrm{S}_{98.4 \mathrm{keV}}$ (counts) to the uranium mass $\mathrm{M}_{\mathrm{U}}(\mathrm{kg})$, and to the $661.7 \mathrm{keV}$ peak net area $\mathrm{S}_{661.7 \mathrm{keV}}$ (counts) i.e. the excitation source intensity:

$$
M_{U}=\frac{S_{98.4 \mathrm{keV}}}{S_{661.7 \mathrm{keV}} \times C_{\text {SXRF }}}
$$

The attenuation correction uses a ratio between the counts in the 79 to $83 \mathrm{keV}$ area of the Compton continuum and in the $661.7 \mathrm{keV}$ peak (net area). This "Compton index", as well as the $\mathrm{C}_{\mathrm{SXRF}}$ sensitivity coefficient, are calculated with the MCNP computer code (see simulation details in section III) for a large range of matrix chemical compositions and densities, representative of the industrial process. A linear correlation is established from these calculations (e.g. in Fig. 3), which allows deducing $\mathrm{C}_{\mathrm{SXRF}}$ of a given drum without knowing its matrix composition, but just using the measured Compton index.

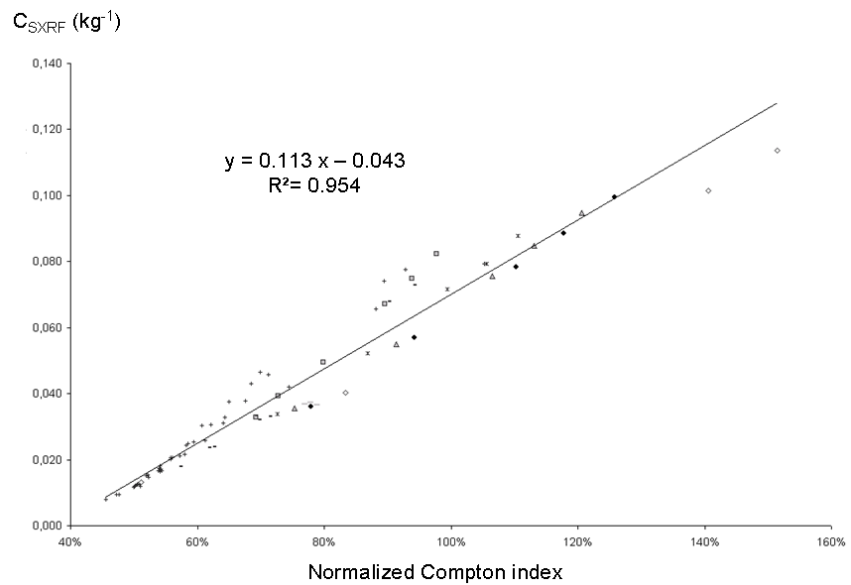

Fig. 3. Correlation between $\mathrm{C}_{\mathrm{SXRF}}$ sensitivity coefficient and Compton index (normalized to a reference matrix) calculated with MCNP for a large range of matrix compositions and for a fixed density of $1.3 \mathrm{~g} / \mathrm{cm}^{-3}$. The uranium and barium masses vary here from 0 to $10 \mathrm{~kg}$ and from 0 to $30 \mathrm{~kg}$, respectively.

Barium was introduced in the industrial process only in 1978. On the other hand, the theoretical matrix provided by the waste producer to CEA to perform feasibility studies showed unrealistically high photon absorption with respect to actual matrices. The correlation of Fig. 4, calculated without this reference matrix and without barium, shows that using a restricted matrix domain based on production periods allows reducing dispersion on $\mathrm{C}_{\mathrm{SXRF}}$, and finally $\mathrm{M}_{\mathrm{U}}$ uncertainty.

Additionally, the bituminous mix density was varied for six matrix compositions (close to the linear fit of Fig. 4 and covering the whole Compton index range) because $\mathrm{C}_{\mathrm{SXRF}}$ strongly depends on the matrix density, see Fig. 5. This last is measured in the gamma radiography station with an uncertainty of $\pm 10 \%$ ( $95 \%$ confidence interval), leading to a significant uncertainty on $\mathrm{C}_{\mathrm{SXRF}}$ and subsequently $\mathrm{M}_{\mathrm{U}}$.

Different collimator apertures can be used, depending on the gamma irradiation level of each drum, to keep the count rate of the HPGe planar detector below $3.10^{4} \mathrm{~s}^{-1}$. Available apertures are $2.52 \mathrm{~cm} \times 2.52 \mathrm{~cm}$ (the one used to calculate correlations of Fig. 3 to 5 ), $1.75 \mathrm{~cm} \times 1.75 \mathrm{~cm}, 1.75 \mathrm{~cm} \times$ $0.5 \mathrm{~cm}$ and $1.75 \mathrm{~cm} \times 0.4 \mathrm{~cm}$. Collimator aperture has a limited but non-negligible influence, see Fig. 6. However, using fast numerical electronics handling higher count rate as the analog electronics implemented for these tests, would allow using a unique collimator for all drums.

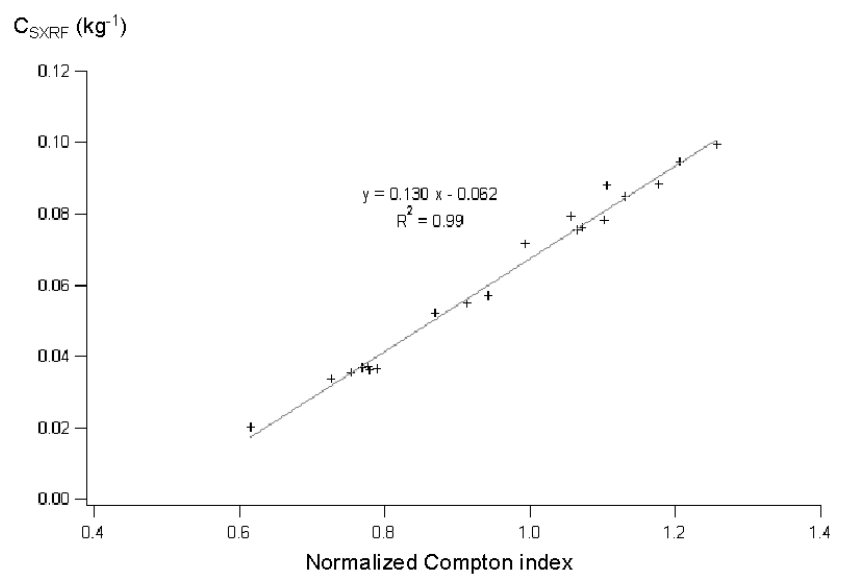

Fig. 4. Correlation between $\mathrm{C}_{\mathrm{SXRF}}$ and the Compton index on a smaller domain of matrix compositions.

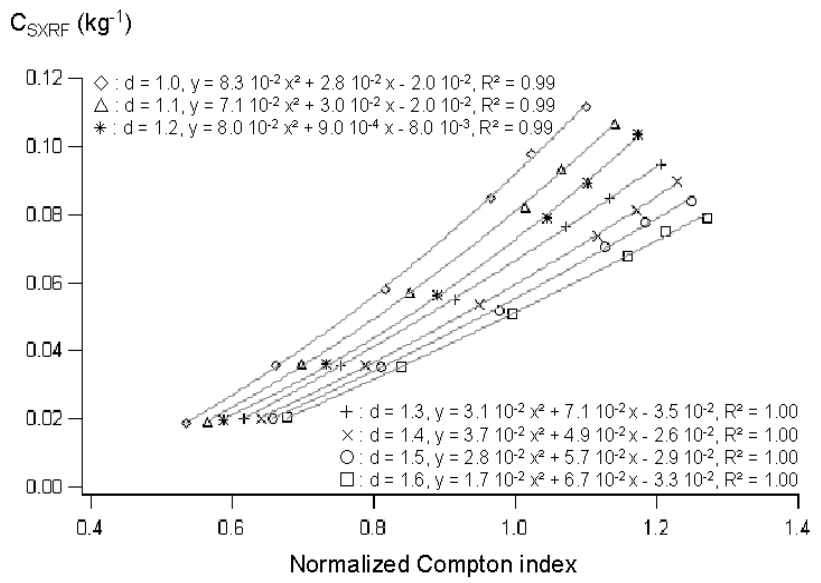

Fig. 5. Effect of density on the $\mathrm{C}_{\mathrm{SXRF}}$ vs. Compton index correlation. 


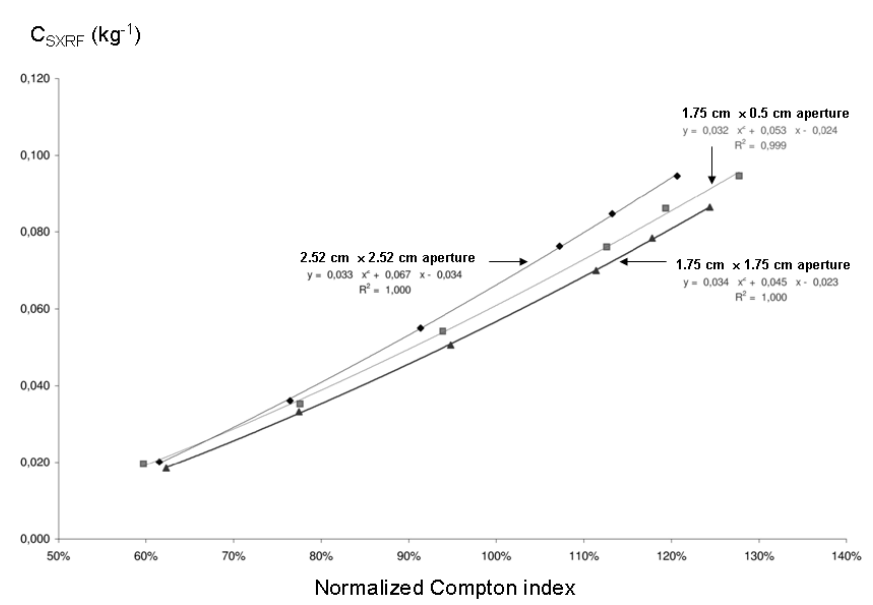

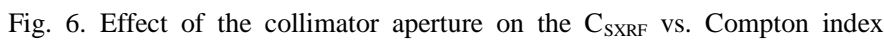
correlation, calculated for the $1.3 \mathrm{~g} . \mathrm{cm}^{-3}$ matrix density. The correlation of the $1.75 \mathrm{~cm} \times 0.4 \mathrm{~cm}$ collimator is not reported as it is almost identical as the $1.75 \mathrm{~cm} \times 0.5 \mathrm{~cm}$ one.

Finally, the total uncertainty on uranium mass determined by SXRF is mainly due to the following causes:

- counting statistics of the $98.4 \mathrm{keV}$ peak net area, which is lower than $\pm 15 \%$ ( $1 \sigma$, one standard deviation) in $20 \mathrm{~min}$ for an uranium mass larger than $1 \mathrm{~kg}$. The statistical uncertainty might be larger for a smaller mass, depending on ${ }^{137} \mathrm{Cs}$ activity and matrix composition, but the effect of uranium on active neutron measurement would then be negligible;

- uncertainty on the measured Compton index, i.e. quadratic sum of relative statistical uncertainties on the $661.7 \mathrm{keV}$ net area and on the 79 to $83 \mathrm{keV}$ integral counts; they are less than $1 \%$ and $3 \%(1 \sigma)$, respectively;

- determination of $\mathrm{C}_{\mathrm{SXRF}}$ using an abacus like the one reported in Fig. 5, due to the uncertainty on matrix density, measured by gamma radiography, and to the dispersion of the points around the fit, see Fig. 3 and 4. A conservative uncertainty of $\pm 40 \%$ ( $95 \%$ confidence interval) is arbitrarily attributed to $\mathrm{C}_{\mathrm{SXRF}}$. One can note that the relative statistical uncertainty of Monte Carlo calculations performed to establish all correlations is less than $3 \%$, both on Compton indexes and on $\mathrm{C}_{\mathrm{SXRF}}$ sensitivity coefficients.

Finally, the uranium mass can be estimated by self-induced $\mathrm{X}$-ray fluorescence with an uncertainty of $\pm 50 \%$ (95\% confidence interval). This uncertainty is quite large compared to usual gamma spectroscopy assessments with higher energy photons (e.g. the $1001.0 \mathrm{keV}$ gamma ray if a long acquisition time was possible) but it is sufficient to correct for uranium interference in the pulsed neutron assessment of ${ }^{239} \mathrm{Pu}$. The correction indeed concerns a secondary delayed neutron signal due to induced fissions of ${ }^{238} \mathrm{U}$ [1]. It improves the extraction of the ${ }^{239} \mathrm{Pu}$ mass from the prompt and delayed neutron signals, which mainly depend on ${ }^{235} \mathrm{U}$ and ${ }^{239} \mathrm{Pu}$. The total uncertainty on the ${ }^{239} \mathrm{Pu}$ mass does not only depend on this correction, but on many other parameters like the knowledge of the matrix composition. It is about $50 \%$ for a typical drum containing about $1 \mathrm{~g}$ of ${ }^{239} \mathrm{Pu}$ and $1 \mathrm{~kg}$ of uranium [1]. A similar uncertainty is obtained for the other major contribution to alpha activity in these drums, i.e. ${ }^{241} \mathrm{Am}$, the assessment of which being performed with the low-energy $59.5 \mathrm{keV}$ gamma ray and the peak-to-Compton method [7].

\section{SiMULATION Vs. EXPERIMENT}

The low energy spectrometer of Fig. 1 was modeled using the MCNP Monte-Carlo transport code [8]. Calculation is performed in two steps to improve statistical convergence.

An isotropic $661.7 \mathrm{keV}$ photon source is first uniformly sampled in the homogeneous bituminous mix and the photon current (MCNP F1 tally), or flux (F2 tally), is calculated on the HPGe detector entrance surface. This last is located $180 \mathrm{~cm}$ away from the drum axis, behind the $75 \mathrm{~cm}$ long iron collimator. The collimated geometry and significant photon absorption in the matrix requires using MCNP variance reduction techniques such as the "Weight Window Generator" and the "DXTRAN Sphere". The "Flux at a Point Detector" (F5 tally) is also very efficient, but F1 and F2 tallies better simulate the specific 2D photon distribution on the detector surface due to transmission effects through the edges of the collimator.

The second step consists in calculating the energy distribution of the pulses created in the HPGe planar crystal $(2.54 \mathrm{~cm}$ diameter and $1.3 \mathrm{~cm}$ thickness) by the photon current, or flux, calculated in the first step. We use here the MCNP "Pulse Height" tally (F8), and the measured energy resolution of the HPGe detector is taken into account with the MCNP GEB ("Gaussian Energy Broadening”) card.

Calculated and experimental spectra of drums \#3 and \#5 are reported in Fig. 7 and 8, respectively. Each experimental spectrum is the sum of the four segmented spectra recorded successively in each sector of the drum, as explained in the paragraph below Fig. 1.

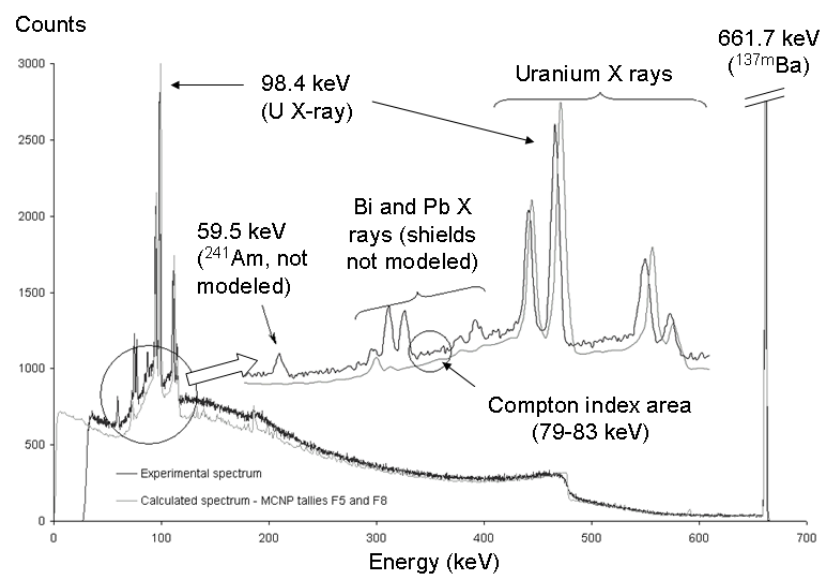

Fig. 7. Simulation $\left(1^{\text {st }}\right.$ step with tally $\mathrm{F} 2$ and $2^{\text {nd }}$ step with tally $\left.F 8\right)$ and experimental spectra of drum \#3 measured with the $1.75 \mathrm{~cm} \times 1.75 \mathrm{~cm}$ collimator. 


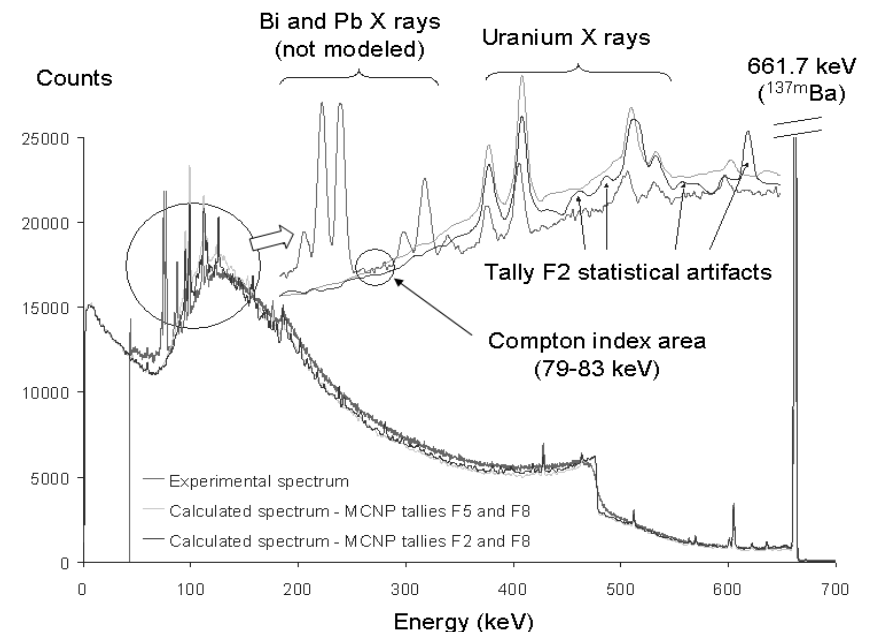

Fig. 8. Simulation ( $1^{\text {st }}$ step with tally F2 or F5, and $2^{\text {nd }}$ step with tally F8) and experimental spectra of drum \#5 measured with the $1.75 \mathrm{~cm} \times 0.5 \mathrm{~cm}$ collimator. Note that statistically non-significant bins occurred in the F2 calculation, leading to nonphysical peaks in the F8 calculation.

It must be noted that the bituminized matrix consists of superimposed homogeneous slices, but each slice can be different from the others in terms of activity and density. Indeed, radioactive sludge is finely mixed with bitumen in an extruder, but it is poured in several steps in the drum to allow cooling down (each slice is $\sim 1 / 4^{\text {th }}$ of the drum). Several drums are successively and partly filled on a carousel, and the nature of the sludge can change before a drum is fully filled. The matrix composition being unknown in each sector, we compare the sum spectrum to numerical simulation performed with an average matrix composition.

For drums \#1 and \#3, the matrix composition of the bituminous mix $(\mathrm{C}, \mathrm{O}, \mathrm{H}, \mathrm{S}, \mathrm{Fe} \ldots)$ was determined by radiochemical analysis on samples extracted from the final packages. As we did not have this information for drum \#2, we used the composition of another sampled drum produced in the same period (March 1971). For more recent drums \#4 (1997) and \#5 (1998), composition was determined by radiochemical analyses performed on radioactive sludge before mixing with bitumen (online quality controls). As already mentioned, however, only the average over one year of production was available for drum \#4.

Besides low $\mathrm{Z}$ elements of the bituminous mix $(\mathrm{C}, \mathrm{O}, \mathrm{H}, \mathrm{S}$, $\mathrm{Fe} . .$.$) , the uranium mass in drums \# 1, \# 2$ and \#3 was determined by long gamma-ray spectroscopy measurements using the $1001.0 \mathrm{keV}$ line. This was not possible for drums \#4 and \#5 because of ${ }^{154} \mathrm{Eu}$ interfering gamma rays at 996.3 and $1004.7 \mathrm{keV}$, and therefore the uranium mass was determined by online radiochemical analyses. It can be noted that for drums \#1 and \#3, the uranium mass assessed by gamma-ray spectroscopy and by radiochemical analyses are in agreement within 5\%, this difference being much smaller than measurement uncertainties.

The main features of the gamma spectra reported in Fig. 7 and 8 are quite correctly reproduced by calculation: $661.7 \mathrm{keV}$ full-energy peak, Compton edge and continuum, uranium $\mathrm{X}$ rays. Bismuth and lead $\mathrm{X}$ rays are globally absent of simulated spectra because BGO and external lead shield are not modeled. For drum \#3, simulation just shows small peaks associated to lead fluorescence, lead being present in tiny quantity in the bituminous matrix. Table II shows the ratio between calculated and measured $\mathrm{C}_{\mathrm{SXRF}}$ sensitivity coefficients. The agreement is quite correct taking into account modeling uncertainties, especially concerning matrix composition. For instance, the uncertainty on barium mass for drum \#4 significantly influences calculated $\mathrm{C}_{\mathrm{SXRF}}$. In addition, the largest discrepancy between simulation and experiment is observed for drum \#2, for which the matrix composition was not directly measured, but is supposed to be similar to another drum produced in the same period.

TABLE II. CALCULATED AND EXPERIMENTAL $\mathrm{C}_{\text {SXRF }}$ SENSITIVITY COEFFICIENTS.

\begin{tabular}{cccc} 
Drum & $\begin{array}{c}\text { Measured } \\
\mathrm{C}_{\text {SXRF }}\left(\mathrm{kg}^{-1}\right)\end{array}$ & $\begin{array}{c}\text { Calculated } \\
\mathrm{C}_{\text {SXRF }}\left(\mathrm{kg}^{-1}\right)\end{array}$ & Ratio \\
\hline$\# 1$ & 0.23 & 0.24 & 0.96 \\
$\# 2$ & 0.30 & 0.21 & 1.43 \\
$\# 3$ & 0.14 & 0.14 & 1.00 \\
$\# 4$ & 0.09 & $0.11^{\mathrm{a}}$ & 0.82 \\
$\# 5$ & 0.10 & $0.08^{\mathrm{b}}$ & 1.13 \\
\#5 & 0.12 & 0.83 \\
\hline${ }^{a}$ With 5.6 kg Ba and ${ }^{b}$ with 9.4 kg of barium, see Table I.
\end{tabular}

On the other hand, 20 real waste drums produced between 1968 and 1972 have been measured before the construction of the measurement system used in this paper. Owing to their low ${ }^{137} \mathrm{Cs}$ activity (a few GBq), it was possible to use unshielded HPGe detector in open geometry and to detect uranium $\mathrm{X}$ rays with long acquisitions. Therefore, we simulated these 20 measurements with MCNP to complete the above qualification of numerical simulations. Here, we used in the model the activity of ${ }^{137} \mathrm{Cs}$ and the mass of ${ }^{238} \mathrm{U}$ determined by gamma spectroscopy with the $661.7 \mathrm{keV}$ and $1001.0 \mathrm{keV}$ peaks, respectively. For 6 of the 20 drums (including drums \#1 and \#3 mentioned above), the matrix chemical composition was determined by radiochemical analyses on extracted samples. For the 14 other drums (including drum \#2), it was deduced from the production period. The calculation-to-experiment ratio for the $98.4 \mathrm{keV}$ uranium $\mathrm{X}$ ray ranges from 0.83 to 1.46 for the 20 drums, which is rather satisfactory considering the uncertainty on matrix composition for most of the drums.

Finally, numerical simulation reproduces uranium selfinduced $X$ rays with a satisfactory precision, consistent with the $\pm 50 \%$ uncertainty of SXRF method estimated in section II, the main cause of uncertainty being in both cases the knowledge of the matrix composition.

\section{EXPERIMENTAL QUALIFICATION OF SXRF}

The measured Compton indexes and matrix densities of the five drums are used to infer the $\mathrm{C}_{\mathrm{SXRF}}$ parameters from the abacus of Fig. 5. Equation (1) then provides the uranium mass $\mathrm{M}_{\mathrm{U}}$ of each drum, see Table III, from the $98.4 \mathrm{keV}$ and $661.7 \mathrm{keV}$ net areas. "Reference mass $\mathrm{M}_{\mathrm{U}}$ " comes from Table I (gamma-ray spectrometry or radiochemical analyses). The 
ratios between reference and SXRF uranium masses are consistent with measurement uncertainties.

TABLE III. REFERENCE URANIUM MASS, FROM TABLE I, VS. SXRF ASSAY.

\begin{tabular}{cccc} 
Drum & $\begin{array}{c}\text { Reference } \mathrm{M}_{\mathrm{U}} \\
(\mathrm{kg})\end{array}$ & $\begin{array}{c}\mathrm{M}_{\mathrm{U}} \text { with SXRF } \\
(\mathrm{kg})\end{array}$ & Ratio \\
\hline$\# 1$ & $0.84 \pm 20 \%$ & $0.84 \pm 50 \%$ & 1.00 \\
$\# 2$ & $3.50 \pm 20 \%$ & $2.98 \pm 50 \%$ & 1.17 \\
$\# 3$ & $7.56 \pm 20 \%$ & $6.37 \pm 50 \%$ & 1.19 \\
$\# 4$ & $0.94[-43 \% ;+21 \%]$ & $1.13 \pm 50 \%$ & 0.83 \\
$\# 5$ & $0.85 \pm 20 \%$ & $0.95 \pm 50 \%$ & 0.89 \\
\hline
\end{tabular}

Table III and the spectrum of drum \#5 in Fig. 8 show that SXRF can detect less than $1 \mathrm{~kg}$ of uranium in $20 \mathrm{~min}$. Comparatively, ${ }^{238} \mathrm{U}$ detection limit using the $1001.0 \mathrm{keV}$ line of ${ }^{234 \mathrm{~m}} \mathrm{~Pa}$ ranges from a few kilograms to dozens of kilograms, depending on waste activity. SXRF detection limit (DL) estimated by numerical simulation ranges from 0.25 to $1 \mathrm{~kg}$ of uranium in $20 \mathrm{~min}$ measurements [4]. The a posteriori DL (in $\mathrm{kg}$ of uranium) can be estimated from the gamma spectrum of each measured drum:

$$
D L=\frac{8.8 \times \sqrt{B_{\text {Compton }} \times F W H M}}{S_{\text {SXRF }} \times \sqrt{T}}
$$

in which $\mathrm{B}_{\text {Compton }}$ is the continuum level in counts per channel (i.e. in $\mathrm{keV}^{-1}$ ) below the $98.4 \mathrm{keV}$ peak, FWHM is the Full Width at Half Maximum of this peak $(\sim 1 \mathrm{keV}), \mathrm{S}_{\mathrm{SXRF}}$ is the measured sensitivity in $\mathrm{s}^{-1} \cdot \mathrm{kg}^{-1}$, i.e. the count rate of the $98.4 \mathrm{keV}$ peak (net area) normalized with the reference mass of uranium, $\mathrm{M}_{\mathrm{U}}$, and $\mathrm{T}$ is the measurement time $(1200 \mathrm{~s})$. Results are reported in Table IV, as well as the reference masses of uranium and barium (from Table I) because of their influence on sensitivity.

One can first underline that (2) actually overestimates DL, because the reference (real) uranium mass in each drum is larger than DL, sometimes by a great deal, and therefore $\mathrm{S}_{\mathrm{SXRF}}$ is underestimated. This is especially true for drums \#2 and \#3, the DL of which should be close to drum \#1.

A second important remark is that any increase of ${ }^{137} \mathrm{Cs}$ activity proportionally raises $\mathrm{B}_{\text {Compton }}$ and $\mathrm{S}_{\mathrm{SXRF}}$, diminishing DL as can be seen in (2). Therefore, despite the presence of kilograms of barium in the matrix, DL is very small for drums $\# 4$ and \#5, the ${ }^{137}$ Cs activity of which is about two decades larger than the other drums.

In conclusion, a posteriori DL are far less than $1 \mathrm{~kg}$ of uranium for the five drums which cover a wide range of ${ }^{137} \mathrm{Cs}$ activities and masses of high- $Z$ elements.

TABLE IV. SXRF DETECTION LIMITS IN 20 MIN MEASUREMENTS.

\begin{tabular}{cccc} 
Drum & $\begin{array}{c}\text { Uranium } \\
\text { mass (kg) }\end{array}$ & $\begin{array}{c}\text { Barium } \\
\text { mass }(\mathrm{kg})\end{array}$ & $\begin{array}{c}\text { Detection limit } \\
\text { (kg of U) }\end{array}$ \\
\hline 1 & 0.84 & No Ba & 0.22 \\
2 & 3.50 & No Ba & 0.51 \\
3 & 7.56 & No Ba & 0.49 \\
4 & 0.94 & 5.6 or 9.4 & 0.12 \\
5 & 0.85 & 5.1 & 0.16 \\
\hline
\end{tabular}

\section{CONCLUSION}

Self-induced X-ray fluorescence (SXRF) is a sensitive method allowing uranium characterization in homogenous radioactive bituminized waste drums by passive gamma- and $\mathrm{X}$-ray spectroscopy. The detection limit is well below $1 \mathrm{~kg}$ of uranium in $20 \mathrm{~min}$ with a collimated germanium detector. When the $98.4 \mathrm{keV}$ uranium $\mathrm{X}$ ray is detected with sufficient counting statistics, i.e. for a uranium mass which could influence active neutron measurements (i.e. $\sim 1 \mathrm{~kg}$ and more), the uncertainty on the uranium mass assessed with SXRF is about $\pm 50 \%$ with a $95 \%$ confidence level. The method just requires the knowledge of the bituminized matrix density, other information being present in the gamma spectrum $\left({ }^{137} \mathrm{Cs}\right.$ activity, which is the fluorescence excitation source and Compton continuum, to correct for low energy photon attenuation) and a priori determined by numerical simulation (SXRF sensitivity coefficient as a function of density and Compton index). As a consequence, the method can easily be implemented without hardware modification.

\section{ACKNOWLEDGMENT}

The authors thank COGEMA Marcoule (now AREVA NC) for providing the bituminized drums and their characteristics.

\section{REFERENCES}

[1] B. Pérot, J.-L. Artaud, C. Passard, A.-C. Raoux, "Experimental Qualification With a Scale One Mock-Up of the "Measurement and Sorting Unit" for Bituminized Waste Drums", ASME $20039^{\text {th }}$ International Conference on Radioactive Waste Management and Environmental Remediation (ICEM2003), 21-25 Sept. 2003, Oxford, England. Paper no. ICEM2003-4597, pp. 479-486.

http://dx.doi.org/10.1115/ICEM2003-4597

[2] J-L. Artaud, B. Pérot et al., Assessment of a Compton suppression spectrometer for the measurement of medium and high level radioactive waste packages, Proc. of Monte Carlo 2000 Conference, pp. 419-424, 23-26 Oct. 2000, Lisbon, Portugal.

[3] J-L. Artaud, B. Pérot, B. Chabalier, P. Bonifay, S. Bernard et al., "Compton suppression detector dedicated to the measurement of bituminized waste drums from the Marcoule reprocessing plant using gamma spectrometry", Proc. of ICEM'01, $8^{\text {th }}$ International Conference on Radioactive Waste Management and Environmental Remediation, 30 Sept. - 4 Oct. 2001, Bruges, Belgium.

[4] P. Pin, B. Pérot, et al. "An innovative method for uranium characterization in bituminized waste drums: the self-induced X-ray fluorescence", proceeding of the RADWAP 2002 international conference, September 2002, Würzburg, Germany.

[5] P. Pin, B. Pérot, "Self-induced X-ray fluorescence and peak/Compton comparison: two innovative methods for bituminized waste drum characterization", proceeding of the IYNC 2004 international conference, May 2004, Toronto, Canada.

[6] W.S. Charlton, D. Strohmeyer, A. Stafford, S. Saavedra, A.S. Hoover, and C. Rudy, "The Use of Self-Induced XRF to Quantify the Pu Content in PWR Spent Nuclear Fuel", Proceedings of 31st Annual Meeting of ESARDA, May 26-28, 2009, Vilnius, Lithuania.

[7] B. Pérot, P. Pin, "Characterization of the low-energy photon attenuation in gamma-ray spectroscopy of bituminized radioactive waste drums using a peak-to-Compton ratio", in Nuclear Instruments and Methods in Physics Research A, vol. 671, pp.76-81, April 2012.

[8] J.F. Briesmeister, "MCNP - A General Monte Carlo N-Particle Transport Code, Version 4C", Los Alamos National Laboratory, LA13079-M, 2000. 